NBER WORKING PAPER SERIES

MODELS OF ARBITRATOR BEHAVIOR:

THEORY AND EVIDENCE

Orley Ashenfelter

David E. Bloom

Working Paper No. 1149

NATIONAL BUREAU OF ECONOMIC RESEARCH

1050 Massachusetts Avenue

Cambridge MA 02138

June 1983

The research reported here is part of the NBER's research program in Labor Studies. Any opinions expressed are those of the authors and not those of the National Bureau of Economic Research. 


\section{Models of Arbitrator Behavior: Theory and Evidence}

\section{Abstract}

This paper analyzes and compares arbitrator behavior under conventional and final-offer arbitration. Simple models of arbitrator behavior are developed under each of these alternative mechanisms. These models are estimated and tested using data on the outcomes of both forms of arbitration in New Jersey, a state in which arbitration is mandatory for unresolved pay disputes involving police officer unions and public employers. The major findings are (1) that the high proportion of union victories under final-offer arbitration were generated by a set of impartial arbitrators applying the same standards used in conventional arbitration, and (2) that union bargainers appear to be considerably more risk averse than employer bargainers, with the wage increases under final-offer arbitration having a lower mean and a lower variance than under conventional arbitration.

Orley Ashenfelter

Department of Economics

Princeton University

Princeton, New Jersey 08544

(609) 452-4041
David E. Bloom

Department of Economics

Harvard University

Cambridge, Massachusetts 02138

(617) $495-4690$ 
The arbitration of disputes by third-party neutrals has become a major industry in the U.S. Arbitration's use in the settlement of disputes arising under existing contracts ranges from the settlement of grievances in union-management contracts to the settlement of highly complex disputes between buyers and sellers in commercial contracts. Arbitration is also now widely used to arrive at the terms of new contracts. The use of these provisions for contract, or "interest," arbitration ranges from the highly public disputes between baseball players and club owners to the settlement of public sector labor disputes and the fashioning of divorce settlements.

Since arbitration mechanisms may be designed in several ways, their increased use makes it increasingly important to understand how the differences in arbitration systems may affect outcomes. Our purpose in this paper is to open up the empirical analysis of some simple models of arbitrator behavior under alternative mechanisms and in different economic environments. We do this by studying the outcomes in the first three years of operation of a New Jersey statute that mandates the arbitration of unsettled pay disputes by New Jersey police officers and the municipalities that employ them. This remarkable statute provides for conventional arbitration of pay disputes if the two parties can agree to this, but requires the use of final-offer arbitration if they cannot. Consequently, the results of both mechanisms may be analyzed and compared. 
In proceeding this way we hope to shed light on two related issues. First, arbitration mechanisms are simply one specialized type of legal setting for the settlement of disputes. The setting is analogous to a civil suit with the arbitrator acting as judge. Indeed, each side's "case" is of ten presented to the arbitrator by the parties' attorneys, and the arbitrator produces a written decision after hearing the case. Negotiated settlements are entirely analogous to "out of court" settlements in civil suits, and arbitrated cases are the ones that "go to trial." What is unusual about arbitration systems is that the arbitrator's decisions, and sometimes the proposals made by the parties, are both publicly obtainable and easily reduced to a single numerical magnitude. Consequently, we suspect that a great deal may be learned about the general nature of legal decision-making by quantitative studies of the simpler arbitration prototypes. 1

Second, the growing theoretical literature on the nature of alternative arbitration mechanisms has raised a number of issues whose resolution requires empirical inquiry. In conventional arbitration, for example, the arbitrator fashions an award based on an analysis of the relevant facts and the arbitrator's external judgment of what would comprise a fair award. It has of ten been suggested that this arbitration system generates little useful information from the parties, and causes the parties' settlement offers to diverge, because to do otherwise might prejudice the arbitrator's judgment against the parties' self interests. To remedy this potential difficulty, Car1 
Stevens suggested a system of final-offer arbitration nearly two decades ago. Stevens suggested that in order to induce settlement each party should be required to submlt to the arbitrator a single final offer, and the arbitrator would then be required to select one or the other of those offers without compromise. ${ }^{2}$

In early theoretical work, Crawford observed that if the arbitrator's (exogenously determined) notion of a fair settlement were known to the two parties, then both arbitration mechanisms would almost certainly lead to the same outcome in a zero-sum setting. In conventional arbitration this would happen because whatever negotiated settlement was proposed by one party, the other party would always do better by holding out for the arbitrator's "fair" decision. Thus, all outcomes would colncide with the arbitrator's preference either through negotiation under the threat of arbitration or by arbitzator decision. Assuming the arbitrator selects the final offer closest to his notion of a fair settlement, this would also be the case with final-offer arbitration. Again, whatever proposal was made by one party, the other party could always do better by holding out for the arbitrator's preferred outcome and both parties would inevitably be led to agree on this outcome or see it imposed by the arbitrator. In this scenario, the threat of arbitration effectively determines the outcome of all settlements and, if the parties bear the arbitration costs, the actual arbitration of cases would wither away. 3 Although this might appear to the outsider as the great success of the arbitration system in encouraging the parties to bargain on their own, 
precisely the contrary would be the case. The parties would merely be agreeing to the outcome that is already a foregone conclusion and saving themselves the cost of arbitration.

The key to Crawford's conclusion is, of course, the assumption that both parties know with certainty the arbitrator's preferred outcome. In a series of papers Farber, and Farber and Katz (1979, 1980), have explored the case where the parties are uncertain as to the arbitrator's preferences. In this setting the outcomes under conventional and final-offer arbitration will generally differ. Negotiated settlements and whether these will occur will then depend, in different ways under the two arbitration systems, on the parties' attitudes toward risk, their prior views on the distribution of arbitrator preferences, and other variables.

Distinguishing whether it is more or less reasonable to assume that the parties are certain about arbitrator preferences is equivalent to testing whether the arbitrator's decisions under a final-offer statute are predictable once information on the final offers and the environment of the bargaining unit is known. In this paper we put these issues to an empirical test in an effort to discriminate between the implications of these two theoretical setups. In order to do this we set out simple models of arbitrator behavior under both final-offer and conventional arbitration and provide a method for testing the empirical implications of these models for observed arbitration awards and for the "fairness" of arbitrator behavior. 
I. Models of Arbitrator Behavior

The New Jersey Fire and Police Arbitration Act was approved in May of 1977. The establishment of some kind of arbitration statute followed almost inevitably from the passage in 1968 of legislation that granted New Jersey's public sector employees the right to organize and bargain collectively, but not the right to strike. The difficulty was that in the absence of the right to strike negotiations often went on long after annual municipal budget cycles had been closed. The purpose of the arbitration statute was to ensure that contract negotiations were final by the time of the employer's budget submission date.

To accomplish this purpose employees and employers covered by the Act (mainly police and fire department workers) must begin collective bargaining at least 120 days before the employer's budget submission date. If the parties do not reach an agreement by 60 days prior to this date they may select the conventional arbitration mechanism for settlement of the unresolved issues. If the parties cannot or prefer not to agree to conventional arbitration they are then compelled to have the disputed issues resolved by final-offer arbitration, with the economic issues taken as a single package. 4 Arbitrators are assigned to cases by the New Jersey Public Employment Relations Commission (PERC), which is responsible for administration of the Act. A list of seven members from the PERC's special panel of arbitrators is first circulated to the parties for comment. One of the seven is then appointed to the case, with all 
arbitration fees borne jointly by the parties (subject to a fee schedule approved by the PERC).

\section{A. Arbitrator Behavior Under Final-offer Arbitration}

Under final-offer arbitration the arbitrator is required to select either the union's final offer $w^{u}$ or the employer's final offer $w^{e}$ as the settlement. 5 In order to do this we suppose that the arbitrator has in mind a preferred settlement $w^{a}$. The value of $w^{a}$ is presumably based on the application of subjective principles of equity to the objective considerations of a particular case. ${ }^{6}$ The value of $\mathrm{w}^{\mathrm{a}}$ in any particular arbitration case is, of course, unknown to outside observers. Moreover, in a case resolved by final-offer arbitration $w^{a}$ will never be revealed.

The preferred settlements of arbitrators $\mathrm{w}^{\mathrm{a}}$ will presumably vary across arbitration cases both because of unobserved variations in economic environments and because of differences in arbitrators' assessments of those circumstances. We shall suppose that in a given year $w^{a}$ may be thought of as being drawn from an as yet unspecified distribution function. The simplest mechanism by which an arbitrator in a particular case might select an offer is to choose that party's offer that is closest to $\mathrm{w}^{\mathrm{a}}$. In these circumstances the arbitrator would select the employer's offer if

$$
\text { (1) }\left|w^{a}-w^{e}\right|<\left|w^{u}-w^{a}\right| \text {, }
$$

and select the union's offer otherwise. Since $w^{e}<w^{u}$ or there would be no need for arbitration, (1) implies that the employer's offer is selected if 
(2) $w^{a}<\left(w^{e}+w^{u}\right) / 2$.

Given the established values of the employer and unton final offers, (2) implies that the employer's offer will be chosen if an arbitrator is selected for the case whose preferred settlement is less than the simple average of $w^{e}$ and $w^{u}$. It follows that the probability of an employer victory, $P$, is simply

$$
\text { (3) } \begin{aligned}
P & =\operatorname{Prob}\left[w^{a}<\left(w^{e}+w^{u}\right) / 2\right] \\
& =F\left[\left(w^{e}+w^{u}\right) / 2\right]
\end{aligned}
$$

where $F(\cdot)$ indicates the value of the cumulative distribution function that describes arbitrator preferences. ${ }^{7}$ If we take the distribution of arbitrator preferences to be normal with mean $\mu^{\mathrm{P}}$ and standard deviation $\sigma^{p}$, as we shall do in our empirical work, (3) is simply

$$
\text { (4) } P=N\left[\left(w^{e}+w^{u}\right) / 2 \sigma^{p}-\left(\mu^{p} / \sigma^{p}\right)\right] \text {, }
$$

where $N(\cdot)$ indicates the value of the cumulative standard normal distribution function. Expression (4) is nothing more than a simple probit function, and its parameters are straightforward to estimate by standard maximum likelihood methods. The constant in this probit function is an estimate of $\mu^{p} / \sigma^{p}$, while the coefficient of $\left(w^{e}+w^{u}\right) / 2$ is an estimate of $1 / \sigma^{\mathrm{P}}$. It follows that although the various realized values of $w^{a}$ may not be observed, the parameters of the distribution function from which the arbitrator's preferences are drawn may be estimated from a series of observations on union and employer final offers and arbitrator choices from those of fers. 
It is worth observing that the even-handed arbitrator treatment of union and employer of fers embedded in the decision rule (1) has some immediate superficial plausibility, at least under the New Jersey statute. After all, arbitrator fees are borne by the parties and the parties' choices are taken into account in the selection of an arbitrator from the panel of seven arbitrators initially proposed. Since arbitrators derive considerable income from these fees the decision rule (1) may be the best viable strategy for maximizing an arbitrator's income over any long-run period. 8

A major objection to the even-handed arbitrator treatment implied by (1), is that it rules out arbitrator bias as might be indicated by the asymmetric treatment of union and employer final offers. As it turns out, the presence of this form of arbitrator bias may be tested for empirically. Suppose, for example, that the employer's offer is accepted if

$$
\text { (5) } \alpha\left|w^{a}-w^{e}\right|<\left|w^{u}-w^{a}\right| \text {, }
$$

where $\alpha>0$. In this setup arbitrators demonstrate a pro-union, proemployer, or no bias as $\alpha>1, \alpha<1$, or $\alpha=1$. With this specification the probability that an employer's offer is accepted is

$$
\text { (6) } P=N\left\{\left[\alpha /(1+\alpha) \sigma^{p}\right] w^{e}+\left[1 /(1+\alpha) \sigma^{p}\right] w^{u}-\mu^{p} / \sigma^{p}\right\} \text {. }
$$

Equation (6) does nothing more than free up the coefficients on $w^{e}$ and $w^{u}$ in the probit function. The ratio of these coefficients is an estimate of $\alpha$, while their sum is an estimate of $1 / \sigma^{\mathrm{p}}$. We shall test the hypothesis $\alpha=1$ in the empirical work below. 
An alternative objection to the decision rule (1) is that it implies that arbitrator notions of falrness do not explicitly take account of the parties' final offers. It is not hard to see, however, that so long as the arbitrator weighs the employer and union offers symmetrically the decision rule (1) is observationally equivalent to an entire class of rules where the arbitrator does take these of fers explicitly into account. Suppose for example that the arbitrator's preference $\tilde{w}^{a}$ is formed as

$$
\text { (7) } \tilde{w}^{a}=\gamma w^{a}+(1-\gamma)\left(w^{e}+w^{u}\right) / 2 \text {, }
$$

with $0<\gamma<1$. Here $\tilde{w}^{a}$ is a weighted average of $w^{a}$, the arbitrator's preference in the absence of information on the offers, and the midpoint of the final offers. The employer's offer is accepted if $\left|\tilde{w}^{a}-w^{e}\right|<\left|w^{u}-\tilde{w}^{a}\right|$ which will be the case if

$$
\tilde{w}^{a}=\gamma w^{a}+(1-\gamma)\left(w^{e}+w^{u}\right) / 2<\left(w^{e}+w^{u}\right) / 2,
$$

or $1 f$

$$
\text { (8) } \gamma w^{a}<\gamma\left(w^{e}+w^{u}\right) / 2 \text {. }
$$

The condition (8) is, of course, identical to (1). From an empirical point of view, therefore, there is an infinite set of symmetric arbitrator decision-making processes that all lead to the same observationally equivalent decisions. In this sense the decision rule (1) may be a very robust empirical device. 
It is worth observing that the structure of the empirical analysis varies slightly when arbitrators use decision rule (5) but when arbitrator notions of fairness are formed according to equation (7). In this case the probability that an employer's offer is accepted is

(9) $P=N\left\{\delta_{1} w^{e}+\delta_{2} w^{u}-\mu^{p} / \sigma^{p}\right\}$,

where $\delta_{1}=[\alpha /(1+\alpha)-(1-\gamma) / 2] / \gamma \sigma^{p}$ and $\delta_{2}=[1 /(1+\alpha)-$ $(1-\gamma) / 2] / \gamma \sigma^{p}$. By comparison it is clear that equations (9) and (6) are observationally equivalent and that $\alpha$ and $\gamma$ are not separately Identified in the latter formulation. Nevertheless, as with (6), the sum of the coefficients of $w^{e}$ and $w^{u}$ in (9) is an estimate of $\sigma^{p}$, implying that $\mu^{p}$ is identified, and the equality of the coefficients $\delta_{1}$ and $\delta_{2}$ continues to provide a test of the hypothesis $\alpha=1$.

The test of the hypothesis $\alpha=1$ is mainly a test of the decision rule (1) under the maintained hypothesis that the distribution function characterizing the $\mathrm{w}^{\mathrm{a}}$ may be taken to be normal. To this point, however, we have not attempted to characterize this distribution in any more detail. For many observers, however, a test of the fairness of arbitrators is really a test of whether $\mu^{p}$ is "fair," or of whether arbitrators have the "correct" preferences. Of course, it is difficult to specify the value for $\mu^{p}$ that would be fair, but it is not difficult to make $\mu^{p}$ a function of some specified set of variables whose coefficients can be estimated. For the $i^{\text {th }}$ observation we may write $\mu_{i}^{p}=x_{i}{ }^{p}$ to get the probit function

$$
\text { (6a) } P_{i}=N\left\{\left[\alpha /(1+\alpha) \sigma^{p}\right] w_{i}^{e}+\left[1 /(1+\alpha) \sigma^{p}\right] w_{i}^{u}-x_{i} \beta^{p} / \sigma^{p}\right\} \text {. }
$$


This merely introduces the variables $x_{i}$ into the probit function. Our estimates of the coefficients in the vector $\beta^{p}$ will indicate how the variables in the vector $x$ determine the mean of the distribution of the arbitrators' notions of what is fair. These estimates may, of course, be compared by the outside observer against any proposed definition of what should determine an average a "fair" award. Indeed, the econometric analysis that follows may be interpreted as nothing more than a scheme for uncovering the nature of arbitrator preferences when only qualitative information on arbitrator awards is available. We consider three main candidate variables to enter the vector $x_{1}$. First, it seems likely that a measure of the wage rate in some alternative occupation may influence an arbitrator's decision. If the relative supply of workers to police departments were very elastic with respect to this alternative wage, the wage structure determined in a competitive market would, of course, guarantee one-to-one movements in the wage rates of police workers and the wage rates in their alternative occupations. For a variety of reasons we doubt that the relative supply of police workers is highly elastic in the short run, but the hypothesis that arbitrators form their notions of a fair award as if it were true has considerable intuitive appeal and seems worth testing. Second, it also seems possible that arbitrators may act to narrow (or occasionally widen) the wage differentials of police workers across municipal jurisdictions. To the extent that this occurs we may expect that an arbitrator's notion of a fair wage increase will be negatively (or occasionally positively) correlated 
with the level of the wage in the previous contract in that municipa1ity. To test this hypothesis we include the level of the previous contract wage as an element of the vector $x_{i} \cdot$ Finally, we consider the impact of the municipality's financial well-being on the arbitrator's decision. We include in the vector $x_{1}$ both the municipality's tax rate and its per capita debt, with the presumption that greater values of both of these variables operate to reduce the arbitrator's notion of a fair award. We conclude by observing that, as we have already noted, the New Jersey statute directs arbitrators to consider all of these items in framing their decisions, but without stipulating how or in what form. It is an empirical question, therefore, as to whether any or all of these variables bear a stable relationship to arbitrator preferences.

\section{B. Arbitrator Behavior Under Conventional Arbitration}

Under conventional arbitration the arbitrator is free to fashion a settlement of his own choosing. As before, we assume that $\mathrm{w}^{\mathrm{a}}$ represents the arbitrator's preferred award in the absence of information on the parties' proposed offers. We consider two alternative schemes by which the arbitrator may fashion and then impose a settlement. 9

The simplest scheme would be for the arbitrator to simply impose his preferred award $w^{a}$ as the settlement. In this case observations on conventional arbitration awards would directly reveal arbitrator preferences. For the $i^{\text {th }}$ arbitration case we would then have 


$$
w_{i}^{a}=\mu^{r}+\varepsilon_{i}
$$

where $\varepsilon_{i}$ has mean zero and standard deviation $\sigma^{r}$. If the mean of the distribution of the arbitrator's preferred settlements varies with some vector of variables $x_{i}$ whose coefficient vector is $\beta^{r}$ this would lead to nothing more than the regression function

$$
\text { (11) } w^{a}=x_{i} \beta^{r}+\varepsilon_{i} \text {, }
$$

which is easily fit to the data on conventional arbitration awards. Alternatively, it may be supposed that the arbitrator attempts to fashion a compromise based on $w^{a}$ and the arguments presented to him by the parties. Suppose that the last offers presented by the parties to each other are $w^{e}$ and $w^{u}$ and that these are made known to the arbitrator. A natural compromise arbitration award would then be

$$
\text { (12) } \begin{aligned}
\tilde{w}_{i}^{a} & =\rho w_{i}^{a}+(1-\rho)\left(w_{i}^{e}+w_{1}^{u}\right) / 2 \\
& =\rho\left(x_{1} \beta^{r}\right)+(1-\rho)\left(w_{i}^{e}+w_{i}^{u}\right) / 2+\rho \varepsilon_{1} \\
& =\rho\left(x_{1} \beta^{r}\right)+v_{1},
\end{aligned}
$$$$
\text { where } v_{i}=(1-\rho)\left(w_{i}^{e}+w_{i}^{u}\right) / 2+\rho \varepsilon_{i} \text {, and } 0<\rho<1 \text {. }
$$

The second line of (12) might also be fit directly as a regression function to the data if $w^{e}$ and $w^{u}$ were observed. In conventional arbitration proceedings, however, these offers are not 
generally known to outside observers, and they may never be stated explicitly by either party in any case. If the unobserved offers $w^{e}$ and $w^{u}$ are correlated with the variables in the vector $x_{1}$, as may well be the case, our regression estimates of $\rho \beta^{r}$ in (12) will suffer from conventional omitted variable bias.

The question naturally arises as to how the models of conventional arbitrator behavior in (11) and (12) might be distinguished empirically. It should be clear that this will not generally be possible without observations on $w^{e}$ and $w^{u}$ when all arbitrators are assigned to conventional arbitration cases. In New Jersey, however, the same panel of arbitrators is used in both conventional arbitration and final-offer arbitration cases. It follows that for this group of arbitrators we may assume $\mu^{r}=\mu^{p}, \sigma^{r}=\sigma^{p}$, and $\beta^{r}=\beta^{p}$. Under these assumptions we may fit equations (6a) and (11) separately and use a test for the equality of these parameters as evidence to favor one or the other of the formulations of (11) or (12). If, for example, the inverse of the standard deviation of conventionally arbitrated awards is equal to the slope of the probit function in (4) we have evidence that arbitrators simply impose upon the parties their notion of a fair award, as in (10). If, on the other hand, this equality is not satisfied in the data we may have evidence that the arbitrators take some account of the unobserved offers of the parties, as in (12).10 
II. Empirical Results

The likelihood function for the final-offer arbitration sample is simply

$$
\text { (13) } L^{p}={ }_{1} \frac{\pi}{\varepsilon} e_{1} P_{1} \frac{\pi}{\varepsilon} u\left(1-P_{1}\right) \text {, }
$$

where $P_{1}$ is given by (6) [or (6a)] and the first product ${ }_{1} \pi e^{P_{1}}$ is taken over employer victorles and the second product ${ }_{1 \varepsilon u}^{\pi}\left(1-P_{1}\right)$ is taken over union victories. The likelihood function for the conventional arbitration sample is simply the likelihood for a conventional regression,

$$
\text { (14) } \left.L^{r}=\pi\left(1 / \sigma^{r}\right) n\left[w_{i}^{a}-x_{i} \beta^{r}\right) / \sigma^{r}\right] \text {, }
$$

where $n(\cdot)$ indicates the standard normal density function. So long as the parameters $\beta^{j}$ and $\sigma^{j}(j=p, r)$ are taken to be different, (13) and (14) may be maximized independently by the usual procedures. In the case where $\mu=\mu^{r}=\mu^{p}$, or $\beta=\beta^{r}=\beta^{p}$, and $\sigma=\sigma^{r}=\sigma^{p}$, however, the likelihood of the combined sample is

$$
\text { (15) } L=L^{p} \cdot L^{r} \text {, }
$$

and the parameters $\mu, \beta$, and $\sigma$ are common to all parts of the 11 kelihood function. 11 


\section{A. Basic Results}

Sample statistics for the basic data are given in Table 1.

These data were collected directly from written arbitration reports. In a few cases all the necessary data were not available in a given report and the observation had to be deleted. Arbitration awards and final offers are given throughout in the form of percentage increases in total compensation.

The sample statistics in Table 1 reveal much of what the econometric analysis w1I confirm. First, the mean of the union and employer final offers is quite low when compared to the mean of the conventionally arbitrated settlements. In 1979 and 1980 the mean of the union offers is about equal to the mean of the conventionally arbitrated settlements, while the mean of the employer offers is more than two percentage points lower. Although not quite so extreme in the data for 1978, this phenomenon shows up there also. If the mean of the conventionally arbitrated cases is taken to indicate the mean of the distribution of arbitrators' preferred settlements, this suggests that the union groups were behaving very conservatively indeed. Second, consistent with this presumption is the fact that in all three years the union offers were accepted in roughly two-thirds to three-quarters of the cases. The result was that actual awards under conventional and final-offer arbitration were not nearly so far apart as the parties' final offers might indicate. Finally, the proportion of cases reaching arbitration droped considerably between 1978 and 1980. This is consistent with the notion that the use of 
Table 1

Means and Standard Deviations of Final of fers and Conventional Arbitration Awards, Police Arbitration Cases, New Jersey, 1978-1980

\begin{tabular}{|c|c|c|c|}
\hline & 1980 & 1979 & 1978 \\
\hline $\begin{array}{l}\text { Mean (and standard deviation) of } \\
\text { Employer Offers (100.w) }\end{array}$ & $\begin{array}{c}5.70 \\
(2.57)\end{array}$ & $\begin{array}{c}6.51 \\
(1.35)\end{array}$ & $\begin{array}{c}5.01 \\
(1.44)\end{array}$ \\
\hline $\begin{array}{l}\text { Mean (and standard deviation) of } \\
\text { Union Of fers (100.w })\end{array}$ & $\begin{array}{c}8.54 \\
(1.46)\end{array}$ & $\begin{array}{c}8.29 \\
(1.73)\end{array}$ & $\begin{array}{l}7.14 \\
(1.12)\end{array}$ \\
\hline $\begin{array}{l}\text { Mean (and standard deviation) of } \\
\text { Final-offer Arbitration Awards }\end{array}$ & $\begin{array}{c}8.10 \\
(1.41)\end{array}$ & $\begin{array}{c}7.57 \\
(1.48)\end{array}$ & $\begin{array}{l}6.63 \\
(1.19)\end{array}$ \\
\hline $\begin{array}{l}\text { Number of Final-0ffer Arbitration } \\
\text { Cases }\end{array}$ & 109 & 92 & 123 \\
\hline Proportion of Employer Victories & .266 & .348 & .317 \\
\hline $\begin{array}{l}\text { Mean (and standard deviation) of } \\
\text { Conventional Arbitration Awards }\end{array}$ & $\begin{array}{l}8.26 \\
(2.14)\end{array}$ & $\begin{array}{c}8.59 \\
(2.32)\end{array}$ & $\begin{array}{c}6.55 \\
(2,23)\end{array}$ \\
\hline $\begin{array}{l}\text { Number of Conventional Arbitration } \\
\text { Cases }\end{array}$ & 32 & 20 & 47 \\
\hline $\begin{array}{l}\text { Proportion of Bargaining Cases } \\
\text { Going to Arbitration }\end{array}$ & .30 & .34 & .49 \\
\hline
\end{tabular}

Source: Authors' tabulation of arbitrator reports. 
arbitration will decline considerably as more is learned by the parties about arbitrator preferences. Between the first and second years of the statute's operation in New Jersey the percentage of negotiations that ended up in arbitration declined from nearly 49 percent to 34 percent. The drop in the utilization of arbitration from the second to the third year of the statute's life was far less dramatic, and it is our casual impression that further declines have been smaller still. This suggests, although the data are not yet available to confirm it, that at least one-quarter of negotiations may continue to end in arbitration even after the parties are thoroughly familiar with the statute's operation.

Table 2 contains the empirical results obtained by maximizing various versions of the likelihood functions (13) - (15) when the variables $x_{i}$ are ignored. These results are perhaps the easiest to interpret and they display much of what the data contain. In column (a) we present the simplest results for each year that correspond to the probit function (4) and the regression equation (10). In these results we impose the constraint $\alpha=1.0$. Consider first the results for 1980. The mean of arbitrator preferences from the final-offer arbitration cases $\left(\mu^{\mathrm{p}}\right)$ is estimated at 8.3 percent, which is considerably higher than the mean of the final offers of the employer groups and only slightly lower than the mean of the final offers of the union groups indicated in Table 1. The standard deviation of arbitrator preferences from the final-offer arbitration cases $\left(\sigma^{p}\right)$ is estimated at 1.5 percentage points and, as (4) shows, this indicates a 


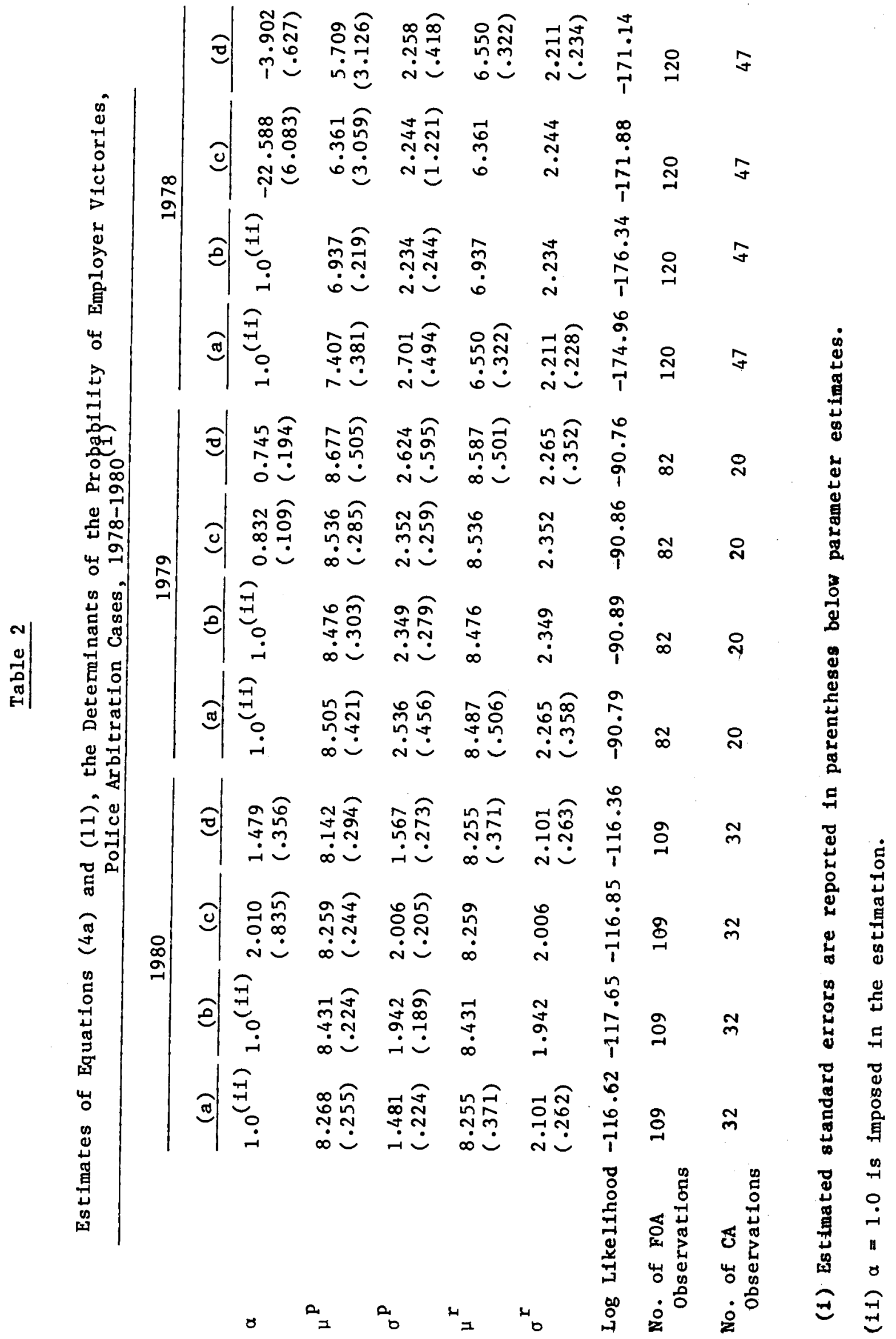


strong positive correlation in the data between the final offers and the incidence of employer victories. The remarkable result in column (a), however, is the extraordinarily close match between the independent estimates of the mean and standard deviation of arbitrator preferences from the conventional and final-offer arbitration cases. This indicates that the coefficient of $\left(w^{e}+w^{u}\right) / 2$ in the probit function (4) is nearly identical to the reciprocal of the standard deviation of the regression errors in equation (10). As Table 1 indicates, precisely the same result holds in the 1978 and 1979 data. A1though not conclusive, this strongly suggests that the settlements in the conventionally arbitrated cases mainly reveal the underlying distribution of arbitrator preferences. The results in the columns labeled (b) are obtained by maximizing the likelihood function (15) in order to test the joint hypothesis $\mu^{\mathrm{r}} \mu^{\mathrm{P}}$ and $\sigma^{\mathrm{r}}=\sigma^{\mathrm{P}}$. As expected, a likelihood ratio test indicates that this hypothesis cannot be rejected in any of the years 1978, 1979, or 1980 .

There is another simple way to state these empirical results. Suppose that we take the mean and standard deviation of the conventional arbitration awards as measures of the mean and standard deviation of arbitrators' preferences $\left(w^{a}\right)$. These assumptions imply that we may predict the actual fraction of employer victories from knowledge of the final offers. Table 2 confirms that these predictions are essentially identical to the maximum likelihood predictions based on the final-offer data alone. Likewise, these same assumptions imply that the correlation between the simple average of 
the union and employer final of fers, $\left(w^{e}+w^{u}\right) / 2$, and the incidence of employer victorles may be predicted from the mean and standard deviation of the conventional arbitration awards alone. We also find this to be the case from the results in Table 2 .

In the columns labeled (c) In Table 2 we continue to maintain the hypothesis $\mu^{P}=\mu^{r}$ and $\sigma^{P}=\sigma^{r}$, and test the hypothesis $\alpha=1.0$. In 1980 the estimate of $\alpha$ is well above unity, while in 1979 the estimate of $\alpha$ is slightly below unity, but in no case can we reject the hypothesis $\alpha=1.0$. In the columns labelled (d) we no longer maintain the hypotheses $\mu^{\mathrm{P}}=\mu^{\mathrm{r}}$ and $\sigma^{\mathrm{P}}=\sigma^{\mathrm{r}}$ and again test the hypothesis $\alpha=1.0$. Again for 1979 and 1980 we can find no evidence for rejection of this hypothesis. This suggests that the unblased decision rule (1) provides a satisfactory fit to the data, at least for 1979 and 1980. The exception is for 1978, where the hypothesis $\alpha=1.0$ may be rejected at any conventional test level. What this finding represents in the data may be stated in a different way. In particular, the results in column (d) of Table 2 for 1978, for example, imply a coefficient (and standard error) for $w^{e}$ in the probit equation (6) of .59 (.07). The estimated coefficient (and standard error) on $w^{u}$ in equation (6a) is $-.15(.04)$, however. These results indicate that the incidence of employer victories was positively correlated with the size of employer final offers in the 1978 data, as expected, but that the incidence of employer victories was negatively correlated with the size of union final offers, which was not expected. In view of the results for 1979 and 1980 we are inclined to attribute the poor 
performance of the simple arbitrator rule (1) in 1978 to the considerable confusion surrounding the Initial implementation of the New Jersey statute. 12 Why and how this would have produced the anomalous empirical results in Table 2 is an issue that requires further research.

\section{B. Further Results}

Table 3 contains unrestricted estimates of the parameters $\beta^{p}$ and $\beta^{r}$ under various specifications for the variables in the vector $x_{1}$. Definitions and descriptive statistics for these varlables are contained in Table 4. Also 11sted in each column are the values for the maximlzed logarithmic likelihood under the constraints $\beta^{p}=\beta^{r}$ and the maximized logarithmic likelihood under the further constraint that $\alpha=1.0 .13$ Testing the hypothesis $\alpha=1.0$ without maintaining ${ }_{\beta^{p}}=\beta^{r}$ may be accomplished by using a straightforward normal statistic computed from the estimate of $\alpha$ and 1 ts estimated standard error in Table 3 .

The rationale for including the variables $S A L, T A X$ and $D E B T$ in the analysis has already been established, but the inclusion of $\triangle P C I$, the percentage change in county income per capita, requires some explanation. As our earlier discussion suggested, we would like to have measured the percentage change in some alternative wage rate in the munfcipality to include in the vector of variables $x_{1}$. At the level of the municipality to which these data refer, however, the best measure of this quantity that we could obtain was the percentage change in per capita income in the county of which the municlpality is 


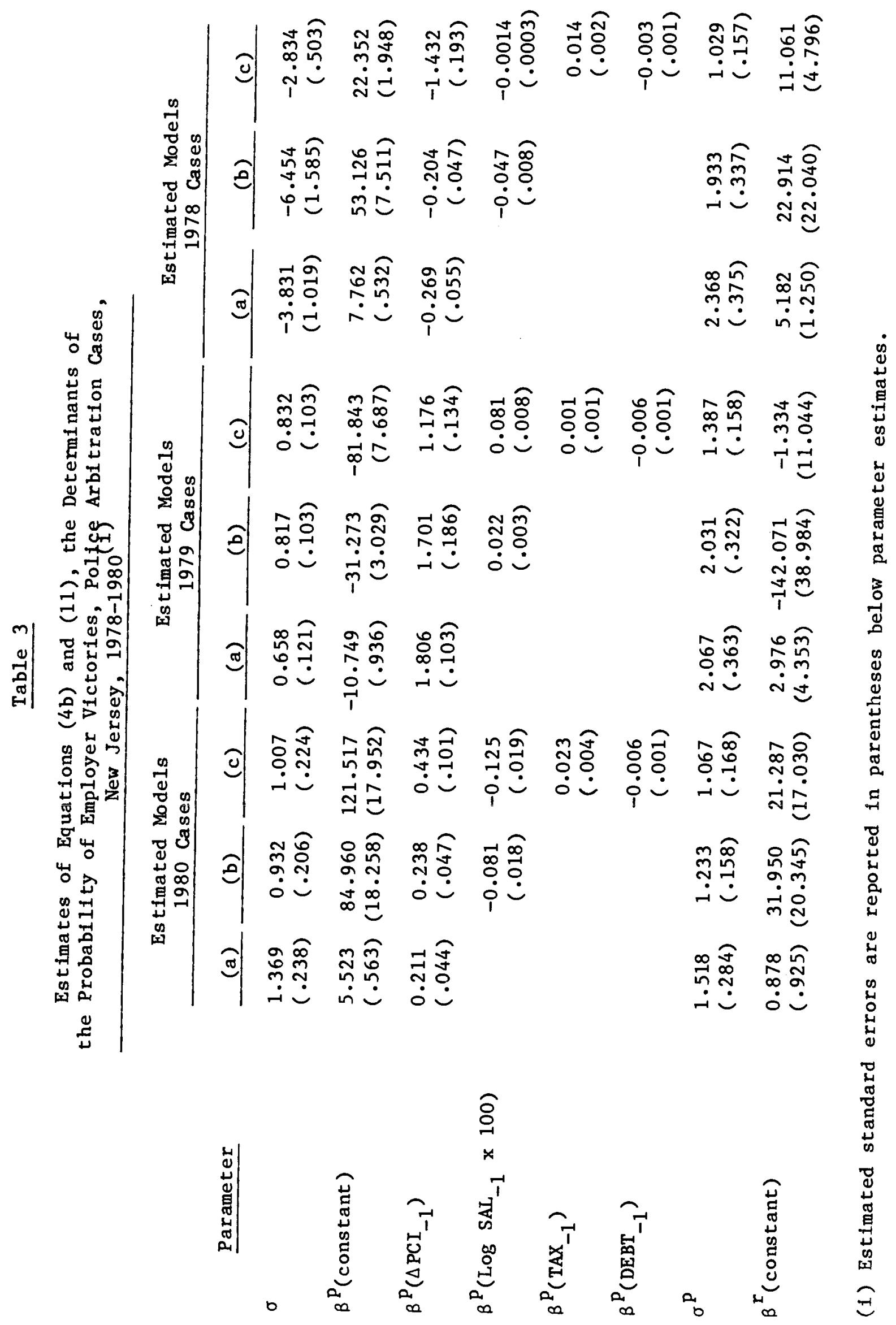




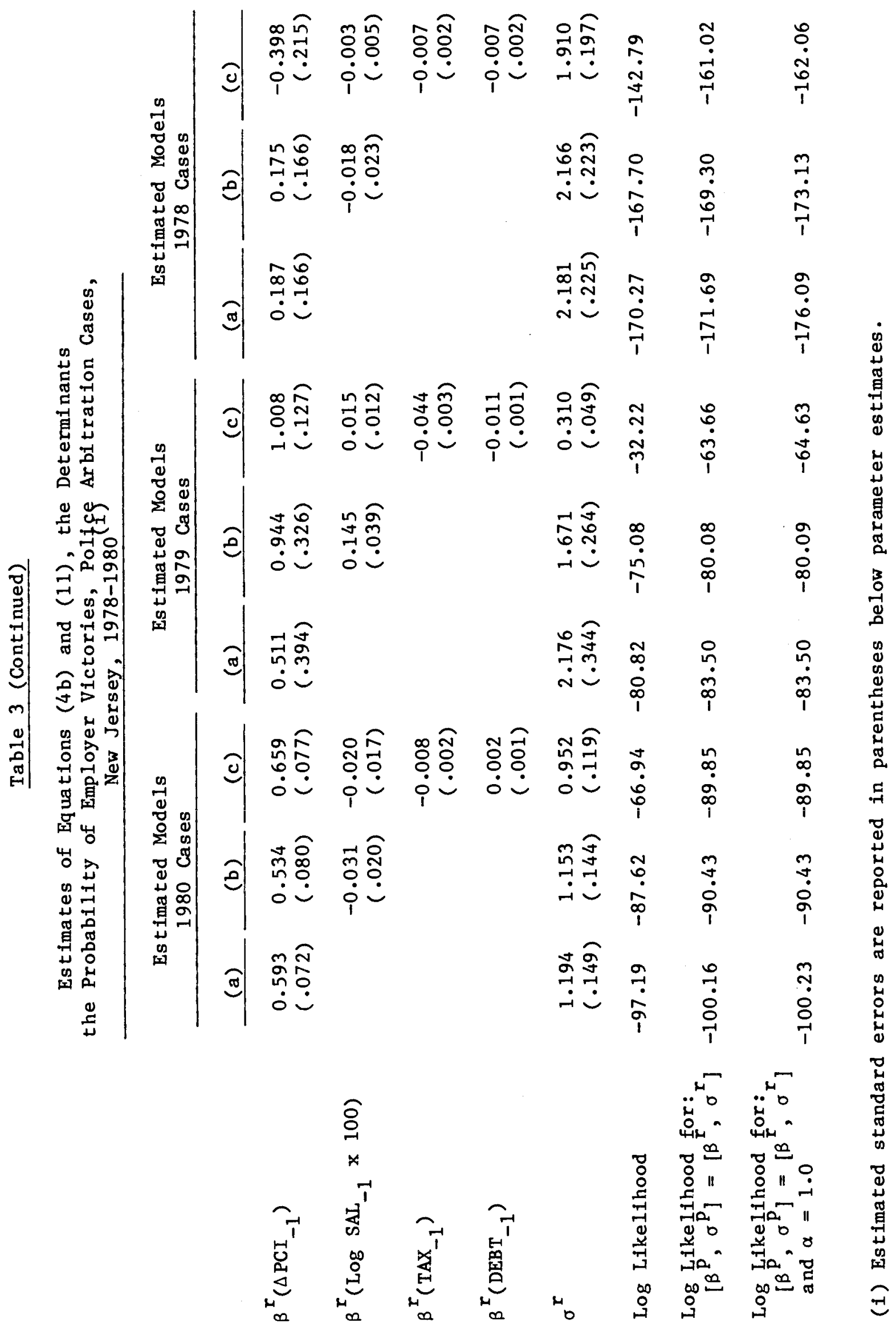


Definitions, Means, and Standard Deviations of the Control Variables Used to Compute the Results in Table 3

\begin{tabular}{|c|c|c|c|c|c|c|c|}
\hline \multirow[b]{2}{*}{ Variable } & \multirow[b]{2}{*}{ Definition } & \multicolumn{2}{|c|}{1980} & \multicolumn{2}{|c|}{1979} & \multicolumn{2}{|c|}{1978} \\
\hline & & $\mathrm{FOA}{ }^{(i)}$ & $\mathrm{CA}^{(\mathrm{i} i)}$ & FOA & $\mathrm{CA}$ & FOA & $\mathrm{CA}$ \\
\hline$\triangle \mathrm{PCI}_{-1}$ & $\begin{array}{l}\text { Lagged percent } \\
\text { change in county } \\
\text { income per capita }\end{array}$ & $\begin{array}{l}12.49 \\
(1.57)\end{array}$ & $\begin{array}{l}12.44 \\
(2.96)\end{array}$ & $\begin{array}{r}10.75 \\
(.77)\end{array}$ & $\begin{array}{l}10.98 \\
(1.26)\end{array}$ & $\begin{array}{l}7.49 \\
(.79)\end{array}$ & $\begin{array}{c}7.30 \\
(1.93)\end{array}$ \\
\hline $\mathrm{SAL}_{-1}$ & $\begin{array}{l}\text { Salary level in } \\
\text { previous year } \\
\text { (in dollars) }\end{array}$ & $\begin{array}{l}18136 \\
(2248)\end{array}$ & $\begin{array}{l}17905 \\
(2095)\end{array}$ & $\begin{array}{l}17091 \\
(2529)\end{array}$ & $\begin{array}{l}15608 \\
(1622)\end{array}$ & $\begin{array}{l}16227 \\
(1966)\end{array}$ & $\begin{array}{l}16278 \\
(2292)\end{array}$ \\
\hline $\mathrm{TAX}_{-1}$ & $\begin{array}{l}\text { Municipality's state } \\
\text { equalized tax rate } \\
\text { in previous year } \\
\text { (in dollars per } \\
\text { loo dollars of } \\
\text { equalized value) }\end{array}$ & $\begin{array}{l}2.58 \\
(.66)\end{array}$ & $\begin{array}{l}2.63 \\
(.76)\end{array}$ & $\begin{array}{l}2.90 \\
(.99)\end{array}$ & $\begin{array}{l}3.11 \\
(.56)\end{array}$ & $\begin{array}{c}3.07 \\
(1.17)\end{array}$ & $\begin{array}{c}4.11 \\
(1.79)\end{array}$ \\
\hline DEBT $_{-1}$ & $\begin{array}{l}\text { Net debt per capita } \\
\text { in municipality in } \\
\text { previous year } \\
\text { (in dollars) }\end{array}$ & $\begin{array}{c}209 \\
(143)\end{array}$ & $\begin{array}{c}250 \\
(174)\end{array}$ & $\begin{array}{c}161 \\
(101)\end{array}$ & $\begin{array}{c}161 \\
(170)\end{array}$ & $\begin{array}{c}190 \\
(127)\end{array}$ & $\begin{array}{c}216 \\
(163)\end{array}$ \\
\hline
\end{tabular}

(1) FOA indicates final-offer arbitration cases.

(ii) CA indicates conventional arbitration cases. 
a part. The use of this variable no doubt entails some measurement error and may result in downward biased estimates of the effect of this variable. A useful future research project would be to remedy this measurement defect, if this is possible.

As Table 3 indicates, the alternative wage variable $(\triangle P C I)$ has a statistically significant and positive effect on the mean of arbitrator preferences in the data for 1979 and 1980 for both the final-offer and conventional arbitration cases. In 1979 the alternative wage coefficient is near to unity for both types of cases, as we had speculated might be the case. In 1980, however, this coefficient is significantly less than unity, and in 1978 it is often negative and occasionally statistically significant. Taken together these results provide some support for the hypothesized importance of alternative wages in the determination of arbitrator preferences, although the results are far from conclusive.

In 1978 and 1980 the level of the previous contract salary has a negative effect on arbitrator preferences that is generally statistically significant. This suggests that in these years arbitrators tended to behave as if they wished to narrow the salary differences across municipalities. In 1979, however, the previous contract salary tends to have a positive effect on arbitrator preferences that is often statistically significant. Taken at face value these results suggest that the arbitrator's perceived role in narrowing (or widening) inter-municipality salary differences may be unstable from year to year. 
Finally, in 1978 and 1979 greater levels of taxation and per capita municipal debt have an unambigously negative and statistically significant effect on arbitrator awards. In 1980 these results are no longer unambiguous; indeed, the (unreported) estimates that constrain $\beta^{p}=\beta^{r}$ generally show no statistically significant effect of per capita debt or taxation on arbitrator awards. These results suggest that the arbitrator's perceived role in responding to municipal taxation or debt burdens is by no means stable from year to year.

In sum, we have found statistically significant, but temporarily unstable effects of alternative wage rates, prior contract wage rates, and per capita debt and taxation variables on arbitrator awards. There are two alternative explanations for these results, but it will take additional research to sort out their empirical validity. First, it may simply be the case that the main predictable variability in the central tendency of arbitrator awards is in their movements through time. If this is the case, then our time-series of estimates of $\mu=\mu^{\mathrm{P}}=\mu^{\mathrm{r}}$ and $\sigma=\sigma^{\mathrm{p}}=\sigma^{\mathrm{r}}$ for each year should ultimately provide the data for a more complete explanation of the basic variability in arbitrator preferences. Considerably more experience with the New Jersey statute will be necessary before there is enough data to make this feasible. Moreover, if this is the explanation for our findings, then most of the parameter estimates in Table 3 do not reveal much, if anything, about the more fundamental determinants of arbitrator decision-making. Indeed, in casual conversations we have found that much arbitrator behavior is characterized as "following the 
herd," or "looking up and down the street," and the results in Table 3 may simply be a description of this behavior rather than an explanation of $1 t$.

An alternative explanation is that there are stable relationships between arbitrator preferences and some set of variables $x_{1}$, but that in our analysis important variables have been omitted from $x_{1}$. Only data from a better experiment than we have available can confirm or refute this possibility.

The remaining results in Table 3 confirm the major findings in Table 2. In 1979 and 1980 the hypothesis $\alpha=1.0$ is clearly accepted by the data, although for 1978 it clearly is rejected. On the other hand, the joint constraints $\beta^{p}=\beta^{r}$, and $\sigma^{p}=\sigma^{r}$ are occasionally rejected in the various specifications for $x_{1}$ that are tested in Table 3. We are inclined to attribute this to the very small samples (especially for conventional arbitration) avallable for estimating the fully unconstrained models. No doubt larger samples and a more detailed set of variables for the vector $x_{1}$ would increase the power and confidence with which these hypotheses can be tested. Finally, and perhaps most important, the addition of the variables $x_{1}$ to the analysis reduces the estimated unpredictable variability in arbitrator preferences $(\sigma)$. Nevertheless, considerable unpredictable variability remains in all cases. In view of the importance of this issue we have also pursued it by an attempt to account for the individual influence of specific arbitrators. To do this we have estimated equation (4) with separate intercepts for each 
arbitrator. In the probit model these fixed effects are econometrically identified only if an individual arbitrator selected at least one employer offer and one union offer in a given year. Table 5 lists the number of final-offer arbitration cases that satisfy this criterion. There are simply too few conventional arbitration cases to perform the analysis for that group. Depending on the year, the table indicates that nearly one-half of the final-offer arbitration cases are decided by four to seven arbitrators who selected at least one union and one employer final offer.

The results in Table 5 indicate that the introduction of the arbitrator dummies considerably reduces the estimate of the unpredictable variability $(\sigma)$ in arbitrator preferences in 1980 and 1978. Nevertheless, $\sigma^{\mathrm{p}}$ never falls below one percent and is sometimes as high as three percent. This strongly suggests that successful models of the strategic behavior of the parties will almost certainly have to account explicitly for the uncertainty the parties face in arbitrator decision-making.

\section{Conclusion}

The empirical models of arbitrator behavior in this paper are an important first step in the much needed empirical studies of arbitration outcomes that remain on the agenda for further research. More complete models should explain both the determination of the parties' final offers, whether they choose to engage in conventional or finaloffer arbitration, and whether they choose to negotiate a settlement 
Table 5

Estimates of $\sigma^{\mathrm{P}}$ in Equation (4) with $\alpha=1$ and with (and without) Arbitrator Dummies, Police Arbitration Cases, New Jersey, $1978-1980^{(i)}$

\begin{tabular}{|c|c|c|c|c|c|c|}
\hline \multirow[b]{2}{*}{$\sigma^{\mathrm{p}}$} & \multicolumn{2}{|c|}{1980} & \multicolumn{2}{|c|}{1979} & \multicolumn{2}{|c|}{1978} \\
\hline & $\begin{array}{c}4.885 \\
(3.153)\end{array}$ & $\begin{array}{c}2.870 \\
(1.607)\end{array}$ & $\begin{array}{c}3.185 \\
(1.532)\end{array}$ & $\begin{array}{c}3.156 \\
(1.514)\end{array}$ & $\begin{array}{l}2.272 \\
(.821)\end{array}$ & $\begin{array}{l}1.114 \\
(.294)\end{array}$ \\
\hline Log Likelihood & -34.89 & -28.89 & -21.82 & -20.93 & -36.89 & -30.04 \\
\hline $\begin{array}{l}\text { Arbitrator Dummies } \\
\text { Included } \\
\text { (No. included) }\end{array}$ & $\begin{array}{l}\text { No } \\
(--)\end{array}$ & $\begin{array}{l}\text { Yes } \\
(3)\end{array}$ & $\begin{array}{c}\text { No } \\
(--)\end{array}$ & $\begin{array}{l}\text { Yes } \\
(3)\end{array}$ & $\begin{array}{l}\text { No } \\
(--)\end{array}$ & $\begin{array}{l}\text { Yes } \\
(6)\end{array}$ \\
\hline $\begin{array}{l}\text { No. of FOA } \\
\text { Observations }\end{array}$ & $53^{(i i)}$ & $53^{(i i)}$ & 39 & 39 & 65 & 65 \\
\hline $\begin{array}{l}\text { (1) Estimated sta } \\
\text { parameter est }\end{array}$ & $\begin{array}{l}\text { Indard err } \\
\text { imates. }\end{array}$ & ors are $r$ & orted in & parentheses & s below & \\
\hline
\end{tabular}


without arbitration. The simple models of arbitrator behavior presented and estimated with remarkable success here will presumably be a key ingredient to this further research.

We have two important substantive empirical results to report. First, under the New Jersey statute union of fers have been selected most of the time in final-offer arbitration cases.14 This finding has raised immediate questions about the impartiality and integrity of the arbitrators in some quarters. In general, we should expect a fair arbitrator to be one that considered the objective considerations in a particular case and then settled on what, in the arbitrator's own mind, seemed a preferred settlement. Given the arbitrator's preferred award, it seems clear that a falr arbitrator must select whichever final offer is closest to 1 t. Supposing that the union and employer also understand this process, they will use their best estimates of the arbitrator's preference to shape their own offers with the understanding that a higher offer by either party will increase the probability that the employer's offer will be selected. If the parties behave symmetrically, as most of us might have expected, we would expect the union and employer offers to fall equally distant from, but on opposite sides of, the parties' best estimate of the arbitrator's preferred award. In this scenario we should naturally expect the unfon offers to be selected in one-half of the cases. It is this prediction that is strongly contradicted by the facts. It follows that there are two different reasons why union of fers may be disproportionately accepted by the arbitrators. On the one 
hand, arbitrators may not follow the decision process set out above. If this is the case, the integrity of the arbitration system is being seriously undermined. On the other hand, the parties may not typically position themselves equally distant from, and on opposite sides of, the arbitrator's preferred award. This might happen either because unions have a more conservative view of what arbitrators will allow or because unions may be more fearful of taking the risk of loss than are employers.

Our econometric results provide strong evidence, however, that the final-offer arbitration decisions were generated by a set of impartial arbitrators who were systematically applying the same standards used in conventional arbitration cases. The evidence for this is that (a) the proportion of union victories and (b) the correlation between the incidence of union victories and the mean of the union and employer final offers are precisely those predicted from the data on conventional arbitration cases alone. (These are econometric tests of standard cross-equation restrictions.) These results Indicate that arbitrators treat generous employer offers no differently than they treat conservative union offers. Instead, the union offers are most of ten selected because the frequency of conservative union offers is considerably greater than the frequency of generous employer offers. It follows that any critique of the generosity of the final-offer arbitration awards must be based on something other than simple win-loss records. 
Our second Important empirical result is that this conservative union behavior resulted in lower average wage increases under the final-offer arbitration provisions than under the conventional arbitration provisions of the New Jersey statute. Although the union offers are accepted in a vast majority of the final-offer arbitration cases, and so the unions appear to "win" In final-offer arbitration, the actual wage increases in these cases are lower than in the conventional arbitration cases. At the same time, we find considerably less variability in the actual awards under the final-offer arbitration provisions than under the conventional arbitration provisions of the statute. What the union bargainers gave up, therefore, by way of a decrease in the mean award under final-offer arbitration they may have made up by a reduction in its variability. This suggests that union bargainers may be considerably more risk averse than employer bargainers and opens up some interesting possibilities for additional research.

The serious quantitative study of dispute settlement mechanisms has only just begun. Further empirical and theoretical research on the operation of these mechanisms may therefore have an important fmpact on their future design. 


\section{Footnotes}

* Princeton University and Harvard University, respectively. We are grateful for useful discussions of the material in this paper with Christopher Cavanagh, Henry Farber, Richard Lester, Danie1 McFadden, and Jeffrey Tener, and from comments by Vincent Crawford and John Pencavel on an early draft. Daniel Rosenblum provided expert computational assistance. Bloom's research was supported, in part, by a grant from the Ford Motor company to Carnegie-Me11on University, where Bloom was on the faculty of the school of Urban and Public Affairs.

1. For a similar view see especially Landes and Posner's wide ranging discussion of private adjudication systems, and the early paper by Gould .

2. Stevens' remarkable paper raises most of the important issues relevant to the analysis of this arbitration scheme. The use of his system is growing and has already been adopted for the settlement of certain public sector labor disputes in six U.S. states and in Chile and has also been used in settling disputes in major league baseball. James Meade, a prominent member of Britain's new Social Democratic Party, has suggested its use in Great Britain as the enforcement mechanism for a new wage and price monitoring system.

3. See Bloom (1981) for a more complete analysis of the role of arbitration costs. 
4. We analyze only disputes in police work in this paper, as many of New Jersey's fire department are volunteer companies. Other details of the statute are discussed by Bloom (1980).

5. Under the New Jersey statute those issues that may be reduced to a single numerical award are the "economic" issues, and it is these that we examine throughout. "Noneconomic" issues are handled as a separate item under the New Jersey statute, and their analysis raises some difficult issues. In fact, however, most disputes involving police officers in New Jersey have been over pay, so that our focus on economic issues is probably the appropriate one there.

6. In New Jersey, arbitrators are directed to give due weight to an enormously broad variety of factors that includes (1) the interests of the public, (2) relevant comparisons of wages and working conditions, (3) the overall level of compensation already recelved, (4) the financlal Impact of the settlement on the municipality, (5) the cost of living, and (6) the continuity of employment. Considerable discretion is obviously left to individual arbitrators.

7. Although his interpretation is different, equation (3) is identical to Farber's (1980) formulation of a similar problem. Our procedure was to some extent inspired by his.

8. This view of the arbitrator is also suggested by Davis. As this discussion indicates, however, the incentive structure for arbitrators is an issue that deserves further research. Card has 
begun it in his study of grievance arbitration.

9. Both of these are possibilities suggested by Farber (1981).

10. There is one disturbing case where this test may give misleading results. Suppose that (12) is the correct structure for arbitrator preferences, but that the estimates of (11) are biased by the omission of the variables $\left(w^{e}+w^{u}\right) / 2$ so as to cause acceptance of the cross-equation constraints. Although this seems unlikely, the positive correlation that presumably exists between $x_{i} \beta^{r}$ and $\left(w^{e}+w^{u}\right) / 2$ wil1 tend to counteract the attenuating effect of $\rho$ on the parameters estimated (since $0<\rho<1$ ).

11. The likelihood function (15) is identical to that used by Ashenfelter for an altogether different purpose, and its maximization was carried out by similar methods.

12. We initially advanced this explanation for the anomalous findings for 1978 in an earlier draft of this paper that contained data for 1978 and 1979 only. Our findings from the 1980 data obviously reinforced the strength of our belief in this explanation, but only additional data can confirm 1t. There was considerable (perhaps unnecessary) confusion at the outset of the 1mplementation of the New Jersey statute because of an ambiguity in the CAP law then in effect. This law sets a limit on the growth of municipal expenditures and there was initial uncertainty regarding whether this was to be applied uniformly to each budget item, including police salaries. Employers argued that the CAP law did apply to each budget item and that arbitrators were bound by it 
also. Subsequent court decisions made it clear that this was not the case.

13. The fitted coefficients for the constrained results are not reported to conserve space, but they are available from the authors in the form of a photocopied appendix.

14. This phenomenon is not restricted to New Jersey, however. There is evidence of similar behavior in Michigan and Massachusetts, as noted by Ashenfelter and Bloom. 


\section{References}

Ashenfelter, Orley, "Determining Participation in Income-Tested Social Programs," Journal of the American Statistical Association 78 September 1983, forthcoming.

Ashenfelter, Orley and David E. Bloom, "The Pitfalls in Judging

Arbitrator Impartiality by Win-Loss Tallies under Final-offer

Arbitration," Proceedings of the Annual Spring Meeting,

Industrial Relations Research Association, March 16-18, 1983.

Bloom, David E. "Customized 'Fina1-Offer': New Jersey's Arbitration

Law," Month1y Labor Review, September 1980, pp. 30-33.

, "Is Arbitration Really Compatible with Bargaining?"

Industrial Relations 20, Fa11 1981, pp. 233-244.

Card, David, "Arbitrators as Lie Detectors: A Suggested

Interpretation," unpublished paper, Graduate School of Business,

University of Chicago, January 1983.

Crawford, Vincent P. "On Compulsory-Arbitration Schemes," Journa1 of

Political Economy 87, February 1979, pp. 131-160.

Davis, Otto A. "Public and Private characteristics of a Legal

Process: A Comment," The Journal of Legal Studies 8, March 1979, pp. 285-293.

Farber, Henry S. "Splitting-the-Difference in Interest Arbitration," Industria1 and Labor Relations Review 35, October 1981, pp. $70-77$. 
, "Mechanisms for Settling Public Sector Labor Disputes:

A Comparative Evaluation of Conventional Arbitration and Offer Arbitration," unpublished paper, August 1979. , "An Analysis of Final-offer Arbitration," Journal of

Conflict Resolution 5, December 1980, pp. 683-705. and Harry C. Katz, "Interest Arbitration, Outcomes, and the Incentive to Bargain: The Role of Risk Preferences," Industrial and Labor Relations Review 33, October 1979, pp. 55-63.

Gould, John, "The Economics of Legal Conf1icts," Journal of Legal Studies 2, June 1973, pp. 279-300.

Landes, W. and R. Posner, "Adjudication as a Private Good," Journal of Legal Studies 8, March 1979, pp. 235-284.

Stevens, Carl M. "Is Compulsory Arbitration Compatible with Bargalning?" Industrial Relations 5, February 1966. pp. 38-52. 